www.jmscr.igmpublication.org

Impact Factor (SJIF): 6.379

Index Copernicus Value: 79.54

ISSN (e)-2347-176x ISSN (p) 2455-0450

crossrefDOI: https://dx.doi.org/10.18535/jmscr/v6i9.52

Journal Of Medical Science And Clinical Research

IGM Publication

An Official Publication of IGM Publication

\title{
A Case of Rodenticide Poisoning with Acute Fulminant Hepatic Failure: A Case Report
}

\author{
Authors \\ Dr Harshitha. R, Dr Anil Kumar. H \\ RRMCH
}

\begin{abstract}
Rodenticides are a heterogeneous group of compounds that exhibit markedly different toxicities to humans and rodents. They are among the most toxic substances regularly found in homes. Predominant rodenticide exposure is anticoagulant rodenticides, zinc phosphide, thallium, barium carbonate and phosphorous. Ratol is a rodenticide available in most of the households and is a common suicidal or accidental poisoning. Ratol contains 3\% whitephosphorous (yellow phosphorous). White phosphorous is a general protoplasmic poison causing multiorgan failure at lethal doses. Liver injury is common; however, most victims of phosphorous intoxication die before overt lesions develop. White phosphorous lethal dose for humans is around $60 \mathrm{mg}$ $(1 \mathrm{mg} / \mathrm{kg})$. When consumed at lethal doses patients present late (>72 hours of ingestion) with multiorgan dysfunction with high mortality rate (100\%). We hereby present a 34-year-old female, came with history of alleged history of consumption of around $2 \mathrm{~g}$ of Ratol paste 2 days prior to presenting to hospital with complains of nausea and abdominal pain. Her vitals were stable having mild scleral icterus and epigastric tenderness. Liver function tests revealed elevated bilirubin levels and deranged coagulation profile. Other parameters were normal. She was given supportive treatment. Her liver enzymes and coagulation profile improved over next 10 days.
\end{abstract}

\section{Introduction}

Ratol is a rodenticide available in most of the households. It is a common suicidal or accidental poisoning ${ }^{1}$. Ratol contains $3 \%$ white phosphorous (yellow phosphorous) $^{2}$. White phosphorous is a highly combustible luminescent compound ${ }^{3}$. When consumed at lethal doses patients present late (>72 hours of ingestion) with multiorgan dysfunction, with a high mortality rate $(100 \%)^{1}$.

\section{Case Report}

We hereby present a 34-year-old female, who was brought to emergency ward with alleged history of consumption of around $2 \mathrm{~g}$ of Ratol paste 2 days prior to coming to hospital, with 1-day history of nausea, 5-6 episodes of vomiting, abdominal discomfort and generalized weakness. There was no history of yellowish discoloration of skin or mucus membranes or bleeding manifestations. On examination her vitals were within normal limits and had mild scleral icterus. Her icterus increased and developed ascites by $3^{\text {rd }}$ day of admission. She developed flapping tremors by $4^{\text {th }}$ day of admission.

\section{Investigations}

Liver function tests revealed elevated bilirubin levels, elevated liver enzymes and deranged 
coagulation profile. Other parameters were normal. Her liver enzymes which was initially high (>2000 IU) reached to normal range by day 10 of admission while her bilirubin levels increased day by day and peaked by day 10 of admission. Her INR initially was 4.0 initially, increased to $>10$ by $2^{\text {nd }}$ to $3^{\text {rd }}$ day of admission reached to near normal by day 10 of admission.

\section{Trend of Liver Function Test in the patient}

\begin{tabular}{|l|c|c|c|c|c|c|c|c|c|}
\hline Day & $\mathbf{1}$ & $\mathbf{2}$ & $\mathbf{3}$ & $\mathbf{4}$ & $\mathbf{5}$ & $\mathbf{6}$ & $\mathbf{7}$ & $\mathbf{8}$ & $\mathbf{1 0}$ \\
\hline TB(mg/dl) & 5.6 & 7.1 & 7.7 & 9.6 & 10.8 & 13.4 & 13.3 & 12.5 & 16.1 \\
\hline DB(mg/dl) & 2.8 & 3.1 & 3.0 & 6.6 & 8.9 & 12.0 & 8.3 & 8.3 & 9.2 \\
\hline SGOT(U/L) & 2595 & 2019 & 890 & 226 & 160 & 201 & 198 & 136 & 56 \\
\hline SGPT(U/L) & 850 & 828 & 691 & 378 & 258 & 263 & 217 & 163 & 64 \\
\hline ALP(U/L) & 185 & 477 & 489 & 439 & 411 & 479 & 420 & 411 & 113 \\
\hline TP(g/dl) & 5.6 & 4.8 & 4.7 & 4.7 & 4.9 & 5.2 & 5.4 & 5.2 & 6.0 \\
\hline
\end{tabular}

\section{Trend of Coagulation profile in the patient}

\begin{tabular}{|l|c|c|c|c|c|c|c|}
\hline Days & $\mathbf{1}$ & $\mathbf{2}$ & $\mathbf{3}$ & $\mathbf{4}$ & $\mathbf{5}$ & $\mathbf{6}$ & $\mathbf{9}$ \\
\hline PT(sec) & 40.8 & 122 & 102 & 65.8 & 41.5 & 32.7 & 14.5 \\
\hline INR & 4.11 & $>10$ & 10.0 & 7.37 & 4.3 & 3.14 & 1.17 \\
\hline aPTT(sec) & 90.2 & 45.0 & 45.7 & 43.2 & 68.2 & 38.6 & 33.0 \\
\hline
\end{tabular}

\section{Treatment}

She was treated conservatively with intravenous fluids and intravenous antibiotics. She received vitamin-K injections $10 \mathrm{mg}$ intra-venousonce daily according to protocol and received 16 pints of fresh frozen plasma over 4 days. She was started on mannitol infusion and other encephalopathy measures for a brief period when she started to develop early Hepatic encephalopathy features. With this treatment she recovered completely over a period of 10 days.

\section{Discussion}

Rodenticides are a heterogeneous group of compounds that exhibit markedly different toxicities to humans and rodents ${ }^{3}$. They are among the most toxic substances regularly found in homes. Predominant rodenticides include anticoagulant rodenticides and phosphides (aluminium and zinc phosphide) $)^{3}$. Nowadays, white phosphorous is also being used as a rodenticide extensively. Lethal dose of white phosphorous for humans is $60 \mathrm{mg}(1 \mathrm{mg} / \mathrm{kg})^{1,3,4}$. It has been stated that as little as $15 \mathrm{mg}$ can cause symptoms ${ }^{4}$.
Mortality rate for patients who present early with symptoms of nausea and vomiting is $25 \%$, nearly $50 \%$ when both gastrointestinal and CNS symptoms are present and almost $75 \%$ when first manifestation is restlessness, irritability, drowsiness, stupor, or coma ${ }^{5}$. The difference in survival rates most likely reflects the interval between time of ingestion and treatment ${ }^{5}$.

White phosphorous is a general protoplasmic poison causing cardiac, hepatic, renal and multiorgan failure at lethal doses ${ }^{2}$. It is a potent hepatotoxin. Large doses cause shock and cardiovascular collapse ${ }^{3}$. Fulminant toxicity occurs with massive doses of about $>1-2 \mathrm{~g}$ where death occurs within 12-24 hrs with peripheral circulatory collapse without signs of hepatic or renal damage ${ }^{3}$.

Acute poisoning has 3 stages $^{2}$ :

Stage 1: up to $24 \mathrm{hrs}$ - asymptomatic or present with local gastric irritation features ${ }^{2}$.

Stage 2: $24-72$ hrs- symptom free, mild increase in liver enzymes ${ }^{2}$.

Stage 3: after 72 hrs- resolution to death, present with deranged liver functions, acute fulminant failure, coagulopathy, confusion/psychosis/ hallucination/coma, hypotension/tachycardia/300 
arrhythmia/cardiogenic shock, acute renal failure ${ }^{2}$. Liver injury is common; however, most victims of phosphorous intoxication die before overt manifestations ${ }^{1}$. Phosphorous causes periportal hepatic necrosis ${ }^{4}$.

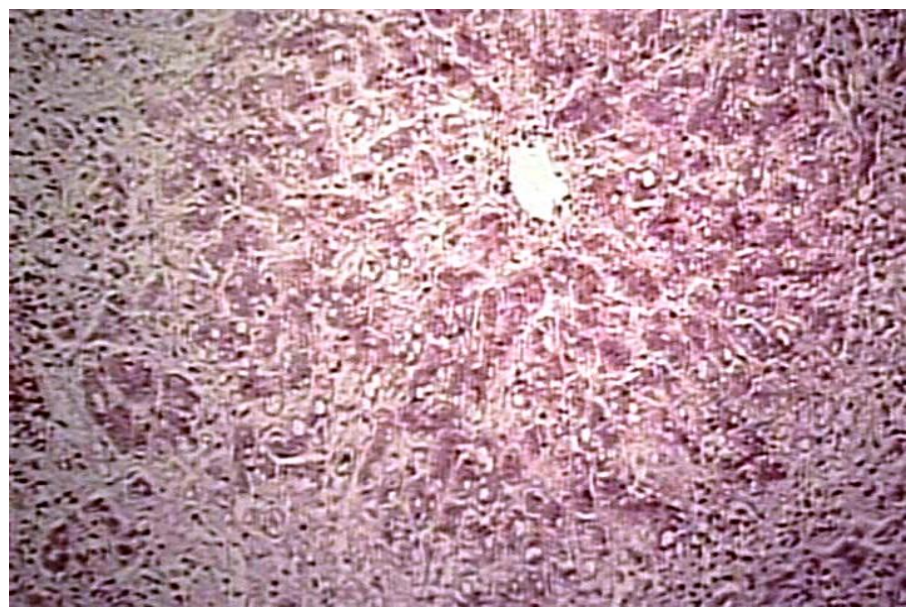

Fig. 1: H\&E staining of liver biopsy illustrating periportal hepatic necrosis

It is difficult to manage patients with white phosphorous poisoning because it gets rapidly absorbed and remains stable in gut for longer period and there is no specific antidote for yellow phosphorous ${ }^{1}$. Treatment is directed at removal of the poison and supportive therapy ${ }^{1}$.

\section{Conclusion}

Anticoagulant rodenticides and phosphides are the most common rodenticide poisoning. Patients present with derangement in coagulation profile or with hemodynamic instability. With increasing focus on aluminium and zinc phosphide, the significance of inorganic phosphorus as a rat poison is often disregarded ${ }^{6}$. Clinicians should be aware that the ingestion of white phosphorous might cause acute liver failure and require more than just primary care. As symptoms occur late (>72 hrs), early detection and treatment of deranged liver function and coagulation profile improves the outcome. Patients must be followed up for 1 week with liver function tests due to late onset fulminant hepatitis.

\section{References}

1. Aniket A Saoji, Anurag S Lavekar et al (2014) A case on suicidal poisoning associated with Ratol and a prospective on yellow phosphorous poisoning. Int. $\mathrm{J}$ of recent trends in Science and Technology Vol-10, Issue 2:223-225.

2. Mauskar A, Mehta K, Nagotkar L, Shanbag P (2011) Acute hepatic failure due to YP ingestion. Indian J Pharmacol 43(3): 355356.

3. Modern Medical Toxicology; $4^{\text {th }}$ edition; V.V. Pillay

4. Gerald. F. Fletcher, John. T. Galambos (1963) Phosphorous poisoning in Humans. Arch intern Med. 112(6): 846-852.

5. McCarron MM, Gaddis GP, Trotter AT (1981) Acute YP poisoning from pesticide pastes. ClinToxicol 18(6):693711.

6. Karanth S, Nayyar V (2003) Rodenticideinduced Hepatotoxicity. JAPI 51. 